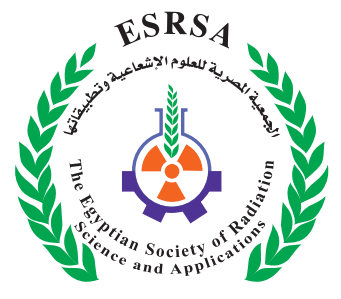

J. Nucl. Tech. Appl. Sci., Vol. 9, PP. 63 : 75 (2021)

\title{
Outlines on Protection of Workers from Ionizing Radiations
}

Salama, S. ${ }^{1}$; Abdelaziz, Y.A. ${ }^{2}$ and Mahmoud, R.M.M. ${ }^{3}$

Received: 26/07/2021

Accepted: 28/11/2021

DOI: $10.21608 /$ jntas.2021.87604.1044

E.mail:engyasserali@yahoo.com

\section{KEYWORDS}

Rules of Radiation

Protection/Ionizing

Radiations/Workers /Risk.

\section{ABSTRACT}

Ionizing radiations resulting from radioactive materials are widely used in many applications in various fields. The industrial applications include: as consumer products, industrial radiography using $\gamma$-radiography cameras and radiography X-ray and nuclear gauging applications. In medicine they are used for diagnosis and treatment in diagnostic radiology, nuclear medicine, radiation therapy and medical radionuclide's as main branches. In science and research can be mentioned: materials science, material irradiation, radiation damage research, crystal colour enhancement, tools for physics, research reactors and nuclear power plants experiments and radioisotopes production. Moreover, radiation is applicable irradiation processed articles, electronics testing, semiconductor - as silicon - production, material characterizations, biological applications, agricultural applications, archaeological applications, and tracer techniques. The workers in these applications are subject to some risks. To minimize these risks and maximize benefits it is necessary to apply radiation protection program to protect those workers. The current paper introduces the main factors for this protection in simply, followed with practical results. Some exposures are acceptable and regulated by the Egyptian Nuclear and Radiological Regulatory Authority (ENRRA).

1. Radiation Protection Department, Nuclear Research Center, Egyptian Atomic Energy Authority, Cairo, Egypt.

2. Reactors Department, Nuclear Research Center, Egyptian Atomic Energy Authority, Cairo, Egypt.

3. Radiation Protection Department, Nuclear and Radiological Safety Research Center, Egyptian Atomic Energy Authority, Cairo, Egypt. 


\section{.INTRODUCTION}

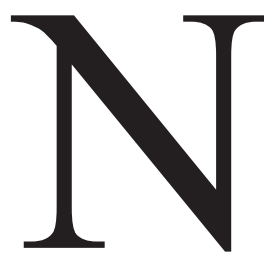

uclear energy is a clean, safe energy source capable of ensuring the continuation of our industrial civilization while protecting the environment as Bruno Comby, the founder and president of the international association of Environmentalists for Nuclear Energy (EFN) said, Bruno Comby (1998). The radiation and nuclear energy have huge capabilities. The use of such energy in different fields becomes important for more than hundred millions of workers in the present time, Bruno Comby (1998), Hellmut Glu) brecht, IAEA bulletin, (2002). In the early years of the $20^{\text {th }}$ century, the ionizing radiation harmful effects to human were observed. Categories of exposure are occupational, public and patients. Exposure to radiation of high doses can cause different harmful effects such as nausea, reddening of the skin or, in severe cases, more acute syndromes within a short period after the exposure. Radiation exposure can also induce somatic effects such as malignancies. In addition, hereditary effects due to radiation exposure have been statistically detected in other mammalian populations and are presumed to occur in human populations, (Annexes C, D and E, United nations, 2011). To protect the workers from the harmful eft fects of ionizing radiations, it is essential to apply the so-called radiological protection program. The program aims to protect the workers, the facility, the public and the environment from the harmful effects of ionizing radiation. Standards references published by the international specialized agencies represent the guidelines to specify the basic requirements for protection against exposure to ionizing radiations and for the safety of radiation sources, international commission on radiological protection by ELSEVI$E R$, (2007) .The aim of the present study is to highlight the main outlines as guide to be follow by the workers in the field of ionizing radiations and their application to protect them against the associated hazardous effects.

\section{RADIATION CONCEPTS}

\section{Types of radiation}

Radiations have a wide range of energies that form the electromagnetic spectrum and particles. Radiations can be classified into two major types:

i. non-ionizing radiation (NIR)

ii. ionizing radiation

This classification mainly depends on the wavelength related to both their frequency and energy. The first type is characterized by longer wavelength, while the second type has short wavelengths. Radioactive energy of (NIR) could cause excitation, but does not produce charged ions. This means that its biological effects to humans are generally limited to thermal damage i.e. burns, International Conference on Non-Ionizing Radiation, Malaysia, (2003). This kind of radiation include ELF (extremely low frequency), radio frequencies, microwave frequencies, lasers, infrared, visible spectrum and ultraviolet. On the other hand, radiation that falls within the "ionizing radiation" type has enough energy to remove tightly bound electrons from atoms, thus creating ions. This is the type of radiation to whom this study is addressed. It has sufficient energy to produce ions in matter at the molecular level. If that matters is a human, significant damage can result including damage to DNA and de nitration of proteins (see Fig 1). Ionizing radiation passes through matter and can cause some of its atoms to become electrically charged, or ionized. This radiation is highly risky because is deposits a large amount of energy into a small area. When are attacks the cells of the body, chemical changes in the DNA cell are produced, leading to abnormal cell growth, (Annexes C, D and E, United nations, 2011). Due to the content of genes/ chromosomes holding information for cell functioning and reproduction that are critical to cell survival DNA must protect from radiation. Radio sensitivity depends on:- cell differentiation degree; phase of the cell cycle at which the irradiation occurs; ra- 
diation quality; dose rate; and dose fractioning, $\mathrm{H}$. Domenech, Chapter 2, Radiation Safety, (2017).

Generally, the radiation effect on body tissues depends on:

- The type of ionizing radiation;

- The received dose and duration of exposure and:

- Internal or external exposure or sum of them collected by the body.

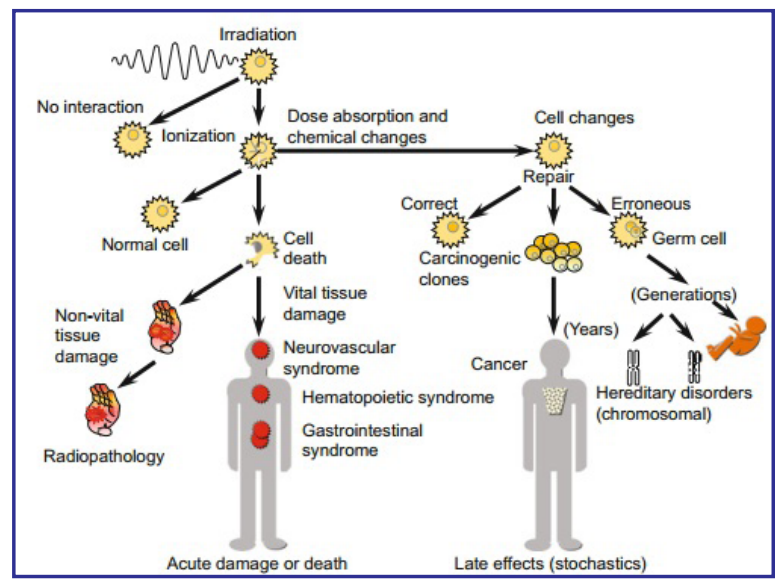

Fig. (1): Radiation Effects on The Whole Body System.

Radiation is an energy traveling through space, in the form of alpha $(\alpha)$, beta $(\beta)$ and neutron (n) particles and $\mathrm{X}$ or gamma $(\gamma)$ rays, Essential of environmental health (2011).

1) (a) Particles - are positively charged particles. They are easily stopped by paper or skin, and are only hazardous if alpha-emitting materials are entering into the body on any path.

2) (B) Particles - are electrons and have a greater penetrating power than alpha particles, but can be stopped by thin layers of aluminum sheet, glass or metal. However, beta-emitting material can be hazardous if entering into the body.

3) (n) Are particles with no charge; neutral, and because of this they can penetrate very easily many materials. They do not produce ionization directly, but their interaction with atoms can give rise to $\alpha, \beta, \gamma$ or $\mathrm{X}$ rays which produce ionization. Thick layer of concrete, water or paraffin can only effectively attenuate neutrons.

4) $(\gamma)$ and $(X)$ rays - are electromagnetic radiations similar to light and radio waves but with shorter wavelengths. They are very penetrating and heavy shielding materials like lead and concrete are needed to attenuate them.

\section{Pathways of Exposure}

\section{Pathways for the public}

Fig. (2) (a and b) shows that the Pathways of Exposure, Human exposure to ionizing radiation may be external or internal. External exposure occurs when a radiation source irradiates a person from outside the body; the person is in the field of radiation. External exposure can result from radiation sources located at some distance from the body surface (e.g. deposited on the ground, suspended in the air). Radiation emitted by radioactive material outside the body exposing the skin, lens of the eye, extremities and the whole body (including internal organs). Internal exposure occurs when a radionuclide is inhaled or ingested, or injected or after it has entered the bloodstream across wound or skin, absorption and exposing internal organs and causing their damage. Once the radionuclide enters the body, internal radiation exposure to the radioactive material will continue depending on its effective half-life $\left(\mathrm{T}_{1 / 2}\right)$. Multiplying the physical and biological half-lives over their sum determines $\left(\mathrm{T}^{1 / 2}\right)$.

The publics exposed to radioactive material through four major exposure pathways, namely:

i. External radiation direct from the clouds.

ii. External dose direct from radioactive materials deposited in the ground.

iii. Internal dose from inhalation radioactive emissions from air.

iv. Internal dose from eating and drinking of radioactive materials present in food and water 


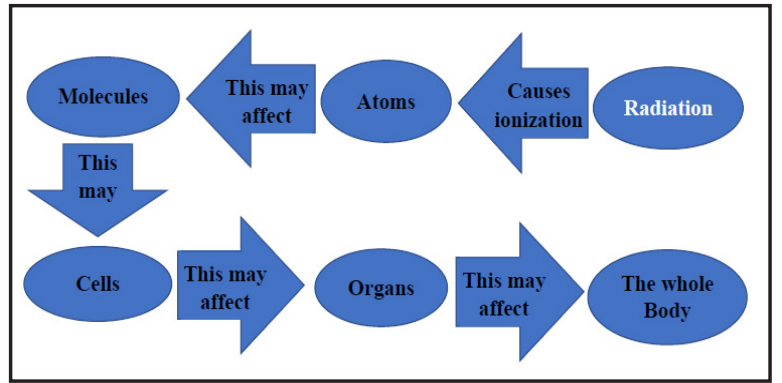

Fig. (2-a): Exposure pathways and routes (adapted from McKone and Daniels, 1991).

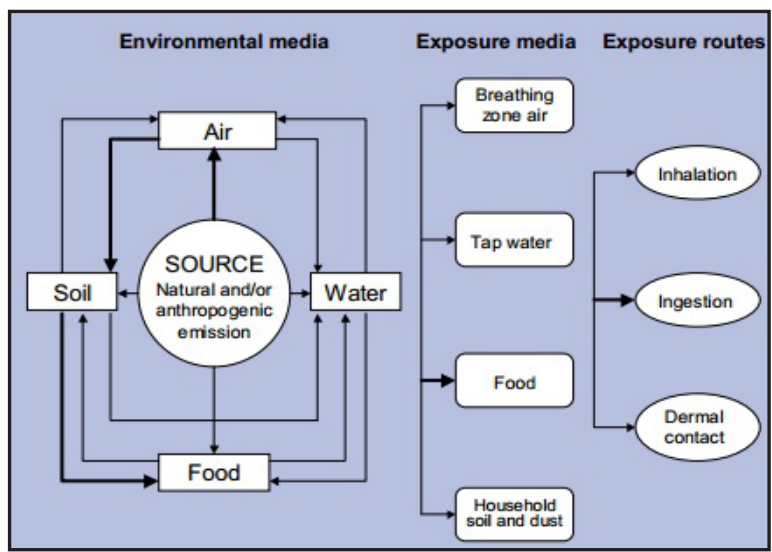

Fig. (2-b): Exposure pathways and routes.

Pathways of Exposure for Workers, international conference, IAEA, (2003).

Ionizing radiation exposure for occupational can occur in any nuclear or radiation facilities such as reactors, radioisotopes production, nuclear fuel cycle facilities, in mining and milling, in medical institue tions, in educational and research establishments and other. Occupational exposure to radiation of workers includes internal and external exposure through the following pathways [Fig. (3)]:

a. Internal exposure through the knowing paths from radioactive material in the workplace,

b. External exposure from radioactive material deposited in the workplace

c. External exposure from radioactive material suspended in the workplace air

d. External exposure from proximity to radiation sources inside the facility. e. Some workers who are handling highly contaminated materials are exposed to radiation from radioactive material deposited on their skin or clothes (external contamination).

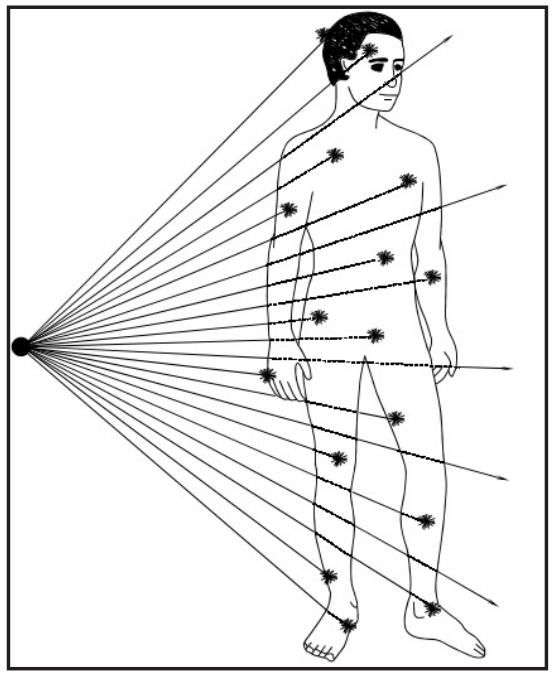

Fig. (3): Exposure types.

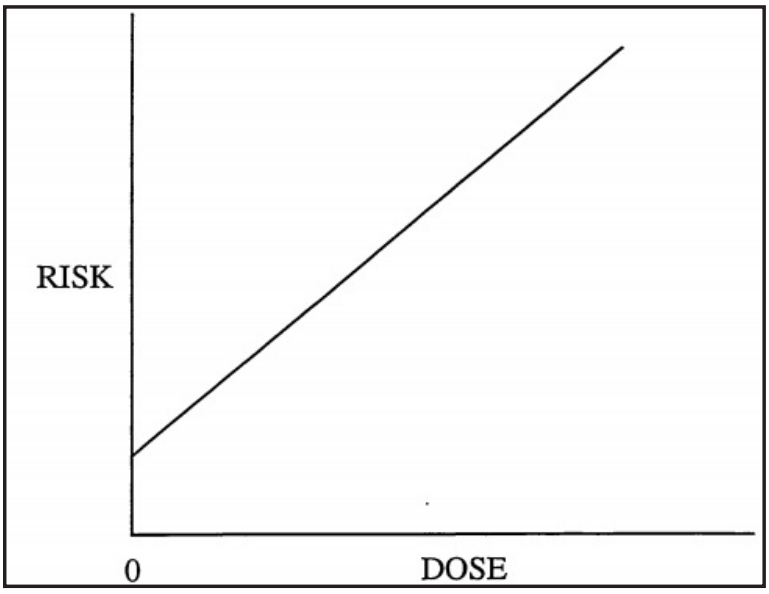

Fig. (4): Linear No-Threshold Risk Model.

\section{Biological Effects of Ionizing Radiation}

The health effects of radiation expressed as biological effects may occur early or late after the exposure to a source of radiation. Whether the source of radiation is natural, or man-made, of small or large dose of radiation; there is a probability to produce some biological effects on human being, Technical Training Center, (2003). Considering the period in which such effects could occur, there are two types of effects: 
i. Short term effects: High levels of radiation can harm exposed tissues of the human body. Such radiations effects can be clinically diagnosed, and are called deterministic effects. Once a radiation dose above the relevant threshold is received, these effects will occur. Their severity depending on how high is the dose [Fig. (4)].

iii. Long-term effects: Studies of populations exposed to radiation, especially of the survivors of the atomic bombing of Hiroshima and Nagasaki, have shown that exposure to radiation can also lead to the delayed induction of cancer and, possibly, of hereditary damage. Effects such as these cannot be confirming in any exposed particular individual, but can be inferred from statistical studies of large populations. They appear to occur at random in the irradiated population. Cancer is the major stochastic effect.

Radiation Exposure Reduction, Radiation Protection Series Publication, (2002).

There are three basic factors could control the radiation exposure according to the golden principle of the radiation protection Time-Distance-Shielding (TDS), as follow:

\section{i. Time:}

Reducing the time of an exposure reduces proportionally the effective dose. Suitable training, helpful tools, pre-planning are good factors to do. A dose can be maintaining ALARA (As Low As Reasonably Achievable) by minimizing the time of exposure to radiation, Canadian Nuclear Safety Commission (CNSC), (2008). Dose is directly proportional to time according to the equation:

Dose $=$ Dose Rate $\mathrm{x}$ Time $\rightarrow$

\section{ii. Distance:}

Increasing the distance reduces dose according to the inverse square law. Appropriate handling tools, tele-probe for survey and radiation survey map are effective here. Radiation is like the light from an incandescent bulb. The further away from the source of radiation (light), the lower the dose rate (the light appears dimmer). Dose rate is inversely proportional to the square of the distance as, Radiation Protection Series Publication, (2002).

$\mathrm{Ir}^{2}=\mathrm{I}_{0} \mathrm{r}_{\mathrm{o}}{ }^{2} \rightarrow(2)$ hence: $\left(\mathrm{I} / \mathrm{I}_{0}\right)=\left(\mathrm{r}_{0} / \mathrm{r}\right)^{2} \rightarrow$

\section{iii. Shielding:}

Shielding is used to reduce the intensity of the radiation' International Basic Safety Standards, Technical Training Center, (2003). Shields of different sources must have a good geometry corresponding to the source shape to be more effective. It may be temporary shielding as lead blankets or permanent shielding as concrete wall. In open pool research reactors, the main pool is filled with water and hot water layer with certain thickness at the top working as a shielding for neutrons. Dose rate is the dose rate with no shielding. The biological shield is use in some facilities to reduce the radiation to a safe level for humans. The radiation is fallings exponentially according to the linear attenuation shielding formula:

$\mathrm{I}=\mathrm{I}_{\mathrm{o}} \mathrm{e}^{(-\mu \mathrm{x})} \rightarrow$

I = intensity with the shield,

$I_{0}=$ intensity without shield,

$\mu=$ linear attenuation coefficient and

$\mathrm{x}=$ thickness of shield

\section{Principles of Radiation Protection}

Any practice subjected to radiation exposure for occupational activity requires justification, optimization and limitation for individuals exposed to ionising radiation, Radiation Protection Series Pubf lication (2002). Laws that are supported by admint istrative measures and enforced by inspectors must be developed to control the radiation exposure of the people and the environment from harmful effects of ionizing radiation now and in the future, without limiting the operation of facilities. The system of protection and safety aims to assess, manage and 
control exposure to radiation through the principles of radiation protection must be apply for all exposure situations, IAEA, General Safety Requirements Part 3, No. GSR Part3 (2008) .The safety principles of such system are:

\section{Principle 1: Responsibility for safety}

The prime responsibility for safety must rest with the person or organization responsible for facilities and activities that give rise to radiation risks.

\section{Principle 2: Role of government}

An effective legal and governmental framework for safety, including an independent regulatory body, must be established and sustained. This is the role of government, International Basic Safety Standards, General Safety Requirements (2008). It has to keep in mind that the performance of the safety falls into the role of the operating organizations ${ }^{(14)}$.

\section{Principle 3: Leadership and management for safety}

Effective leadership and management for safety must be established and sustained in organizations, facilities and activities that give rise to radiation risks.

\section{Principle 4: Justification of facilities and activities}

Facilities and activities that give rise to radiation risks must yield an overall benefit. In Egypt ENRRA, Egyptian Nuclear and Radiological Regulatory Authority, the regulatory body, must ensure authorize the justified practices only' IAEA, general safety requirement, part 7, (2015). In intervention cases, justification means any proposed intervention shall do more good than harm.

\section{Principle 5: Optimization of protection}

Protection must be optimized to provide the highest level of safety that can reasonably be achieved; especially in intervention cases. Optimization maxi- mizes the net benefit by applying the (ALARA) principle aiming to reduce the doses and the cost, IAEA safety standards series no. GS-R-2, (2002).

\section{Principle 6: Limitation of risks to individuals}

Measures for controlling radiation risks must ensure that no individual bears an unacceptable risk of harm, IAEA safety standards series no. GS-R-5 (2009).

\section{Principle 7: Protection of present and future generations}

Workers and the environment, in present and in the future, must be protected against radiation risks, IAEA safety standards series no. GS-R-5 (2009).

\section{Principle 8: Prevention of accidents}

All practical efforts must be made to prevent and mitigate nuclear or radiation accidents. To ensure this prevention, specific arrangements include emergency operating procedures and guidance for the operating personnel should be consider as part of the accident management program of the facility, IAEA, general safety requirement, part 7, (2015). Safety Analysis Report (SAR) should contain complete chapter to analyse postulated initiating events and prepare the written procedure to face any accidents, malfunctioning, or failures that may represent any risk to safety, IAEA safety standards series no. GS-R-2 (2002).

\section{Principle 9: Emergency preparedness and response}

Arrangements must be made for emergency preparedness and response for nuclear or radiation incidents. The preparedness of the facility mentions the needed supporting emergency response, to be usable under emergency conditions, IAEA safety standards series no. GS-R-4, (2009).

Principle 10: Protective actions are essential to reduce existing or unregulated radiation risks. It must be justified and optimized to avoid or to minimize 
severe deterministic effect, IAEA, general safety requirement, part 7, (2015).

All countries, including Egypt, are interested in developing laws to regulate the work with radioactive materials and radiation devices to protect workers and citizens from the dangers due to the misuse of these tools with supporting assistance from the International Atomic Energy Agency, (IAEA).

\section{Dose limits}

The coming limits are derived from national (ENRRA) International Commission on Radiological Protection - ICRP, International Radiation Protection Association - (ICRP, IRPA and IAEA) authorities references.

\section{i. Dose limits for the public}

Public's average annual effective dose (internal + external) should not exceed $1.0 \mathrm{mSv} /$ year, International commission on radiological protection by ELSEVIER, (2007).

\section{ii. Occupational dose limits}

An average annual effective dose of occupational should not exceed $20 \mathrm{mSv} /$ year. It may be accepted to increase the dose up to $50 \mathrm{mSv} /$ years, if the total dose not exceeds doses during any five consecutive years than $100 \mathrm{mSv}$, international comh mission on radiological protection by ELSEVIER (2007). In accordance with the labour law and the requirements of nuclear safety no person under the age of 16 years should be exposed professionally. An annual effective dose for the students and trainees between the ages of 16-18 years must not exceed 6 $\mathrm{mSv} /$ year. On the other hand, due to the increased health risks to the rapidly developing embryo and foetus, the occupational exposure limits to ionizing radiation for the pregnant women can be no more than $5 \mathrm{mSv}$ during the entire gestation period and not more than $0.5 \mathrm{mSv}$ each month, IAEA, general safety requirement, part 7, (2015).

\section{iii. Dose limits for patients}

No limits are present in this case; only the rule of (net benefit/expected harmful) is applicable, international commission on radiological protection by ELSEVIER, (2007).

\section{Emergency Plan}

All radiation practices led to an increase in the radiation level. On the other hand, in the emergency cases, reduction of the high exposure level is required, which knew as intervention. Reducing of the harmful ionizing radiation effect during the accidents requires a continuous training for workers (drills and/or exercises) to perform a successful emergency plan, which differ from place to another according to the type of the potential accidents and the type of ionizing radiation, International Basic Safety Standards, General Safety Requirements (2008).

\section{Egyptian strategy to protect workers from ionizing radiation}

Every state should haven effective national regulatory system for management and protection of workers from exposure to harmful ionizing radiation. The Egyptian strategy to protect workers from exposure to this radiation depends on three main points as follow:

$\mathbf{1}^{\text {st. }}$ all nuclear and radiation facilities, practices and activities in the Arab Republic of Egypt shall exclusively be restricted to peaceful purposes.

$2^{\text {nd }}$. the Egyptian strategy is based on realization of the principle "As Low As Reasonably Achievable" (ALARA), to minimize the risk of radioactive exposure or other hazards, keeping in mind that some exposures may be acceptable.

$3^{\text {ed }}$. The Egyptian Nuclear and Radiological Regulatory Authority (ENRRA) is responsible for performance of the Egyptian strategy for protection the workers in the field of ionizing radiations from their harmful effects. To perform this 
protection the regulation laws should be continuously. Now no licence is given for any facility without ensuring securing the sources and safety of the workers. An operating licence is issue according to the following items:

- The ENRRA now regulates licenses and inspects of any facility where radiation or nuclear sources are use (medical institutions, industrial facilities, research and educational institutions, transport involving radioactive material, nuclear fuel cycle, and field applications with gamma radiography). The aim of these licenses is to minimize the collective doses, to prevent overexposures and to save public health and environment from harmful of ionizing radiation.

- The ENRRA has the right to give licenses to the radiation workers after fulfil the requirements in order to enhance apply the principal of radiation protection to protect the workers, the facilities, the public and environment from ionizing radiae tion damage.

- The ENRRA aims to enforce the protection level by ensure the Radiation Protection Plan (RPP) that includes: activate: individual monitoring, exposure assessments for external and internal exposures, monitoring of the workplace, monitoring techniques, biological dosimetry, recording and reporting procedures according to the nuclear law.

\section{EXPERIMENTAL}

\section{Exposure measurement}

A classification of the exposure types includes occupational, medical and public exposures, Internan tional commission on radiological protection by ELSEVIER, (2007). The amount of radiation received by workers is measured in millisieverts (mSv) every 3 months. Personal external exposure records during three consecutive months in a radiation facility are given in table (1). The majority of the results range between (0.19-0.24) $\mathrm{mSv}$. Few results out of these limits were measured. The values are under the $(0.025)$ of the annual occupational dose limits or $(0.1)$ of a quarter of the annual value. It is expect that these values will increase rapidly with the planned continuous work. The Radiation Personal Month (RPM) will do the best to maintain the values not only below the annual dose limit, but also as low as possible according to ALARA principle.

\section{Area classification}

Area classification is a main item in the RPP of any facility. The facility is classified to areas (Table 2) and zones to prevent contamination dispersion. Each area has its own radiation limits and appropriate personal protective equipment (PPE). There is local rules for entrance and exit from any area to other.

The use of warning or caution signs is necessary to warn unauthorized or unsuspecting personnel of a hazard and to remind authorized personnel as well, (radioactive materials, radiation areas, high radiation areas, and very high radiation areas). The signs and labels should be post in a conspicuous place. It is distributed in the areas according to its classification. The standard radiation symbol appears with the required trefoil symbol as shown below, as shown in Fig. (5).
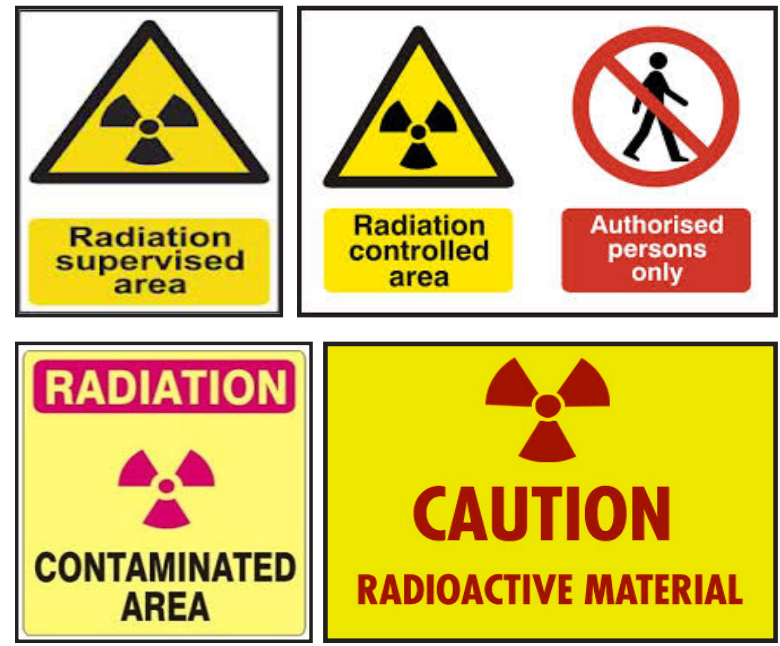

Fig. (5): The standard radiation symbols. 
Table (1) : Personal External Exposure Records during 3 Months.

\begin{tabular}{|c|c|c|c|c|c|}
\hline No & Dose (mSv/3 months) & No & Dose (mSv/3 months) & No & Dose (mSv/3 months) \\
\hline 1 & 0.24 & 8 & 0.22 & 35 & 0.21 \\
\hline 2 & 0.21 & 19 & 0.24 & 36 & 0.19 \\
\hline 3 & 0.20 & 20 & 0.20 & 37 & 0.21 \\
\hline 4 & 0.21 & 21 & 0.21 & 38 & 0.22 \\
\hline 5 & 0.23 & 22 & 0.10 & 39 & 0.19 \\
\hline 6 & 0.22 & 23 & 0.20 & 40 & 0.51 \\
\hline 7 & 0.19 & 24 & 0.20 & 41 & 0.32 \\
\hline 8 & 0.12 & 25 & 0.20 & 42 & 0.19 \\
\hline 9 & 0.21 & 26 & 0.20 & 43 & 0.24 \\
\hline 10 & 0.20 & 27 & 0.19 & 44 & 0.11 \\
\hline 11 & 0.22 & 28 & 0.21 & 45 & 0.26 \\
\hline 12 & 0.18 & 29 & 0.22 & 46 & 0.11 \\
\hline 13 & 0.20 & 30 & 0.23 & 47 & 0.35 \\
\hline 14 & 0.21 & 31 & 0.24 & 48 & 0.23 \\
\hline 15 & 0.19 & 32 & 0.10 & 49 & 0.21 \\
\hline 16 & 0.21 & 33 & 0.19 & 50 & 0.20 \\
\hline 17 & 0.22 & 34 & 0.19 & 51 & 0.21 \\
\hline
\end{tabular}

Table (2) : Dose limits for monitoring area.

\begin{tabular}{|c|c|c|}
\hline \multirow{2}{*}{ Area } & \multicolumn{2}{|c|}{ Dose limits } \\
\hline & $(\mu \mathrm{Sv} / \mathrm{h})$ & $(\mu \mathrm{Sv} / \mathrm{y})$ \\
\hline Free & $<0.5$ & 1000 (public) \\
\hline Supervised & $0.5-3$ & 6000 (occupational) \\
\hline Controlled & $3-10$ & 20000 (occupational) \\
\hline Restricted & $>10$ & $>20000$ (occupational) \\
\hline
\end{tabular}

Routine monitoring that is carried in the work environment could be associated with continuous operations to create not only satisfactory working conditions but also to satisfy the regulatory requirements. If probable contamination of the workplace, such as small spills or spreading (solid, liquid or gases) occurs, it must be immediately identified to overcome this un-required contamination level with fast decontamination.

There are certain limits for contamination of the areas (Table 2). Any contamination should be removed as soon as possible. In all cases, it is necessary that the limit of contamination doesn't exceed the reference limits. If happen, no practices are performing before decontamination to protect the occupational from high contamination. High-contaminated tools should be decontaminated inside glove box using suitable reagents. In urgent cases, the workers who fm the contaminated areas must wear enough PPE for each part of the body subjected to contaminate. The relationship between contamination and dose is not as simple as for external radiation sources. In most cases, (TDS) are not options for reducing 
dose from contamination. Contamination that enters the body through inhalation or ingestion cannot be shielded nor could longer distance be used to reduce the dose. Only time is a factor here If some of the material can be removed from the body, the time of exposure will reduce and so will the dose. It is better to prevent or minimize the contamination from the beginning.

The risk of personnel contamination could be reduced by:

a) Entering contaminated areas only when necessary and authorized.

b) Using PPE properly.

c) Monitoring surfaces for contamination with an appropriate radiation detector.

d) Take care when you handle the high contaminated objects.

e) Conducting a thorough whole-body survey with (HFCM) when exiting contaminated areas.

\section{Surface Contamination}

Fig. (6) presents the surface contamination measured at different years from 2005-2013 in the facility used in this study, which seems to be less than the maximum limit. Limiting value is taken as controlled one. This is good practice.

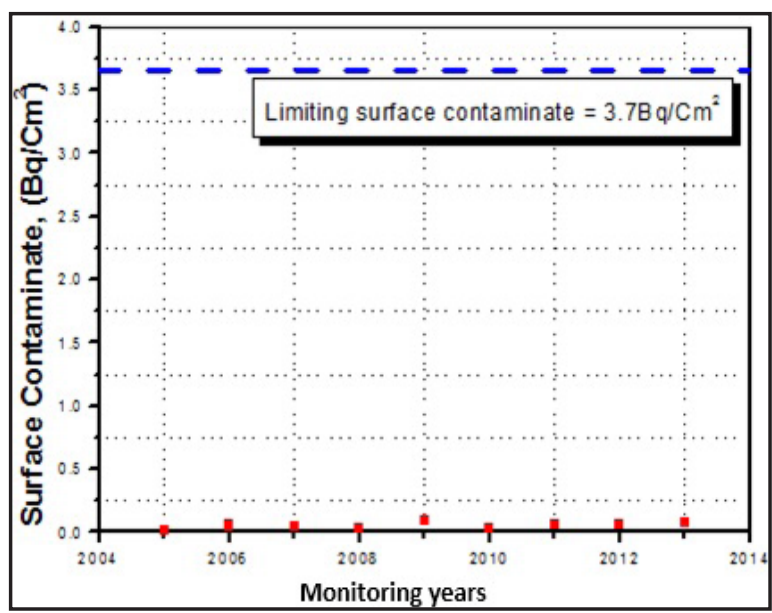

Fig. (6): Monitoring of contamination of controlled area.
Fig. (6) reflects the results of monitoring of controlled area surface contamination. As a local rule, it is recommended washing the hands, may be feet, before leaving the controlled area. In some situation, full shower is necessary. When leaving the controlled area, the workers must be monitor themselves by the whole-body counter or (HFCM) Hand Face Contamination Measuring. If there is any part of the body is contaminated the person clean this part and repeat survey until ensuring no contamination. These steps are doing under supervision.

Fig. (7) Shows the relationship between the results of the radiometric survey of workers inside the controlled area in the mentioned facility. It is clear from the figure that the dash red line represents extent of radioactive contamination allowed for the skin with $\alpha$ high toxicity. The average results of contamination survey conducted confirms that the level of workers skin contamination is much less than the limit, $\left(0.037 \mathrm{~Bq} / \mathrm{cm}^{2}\right)$.

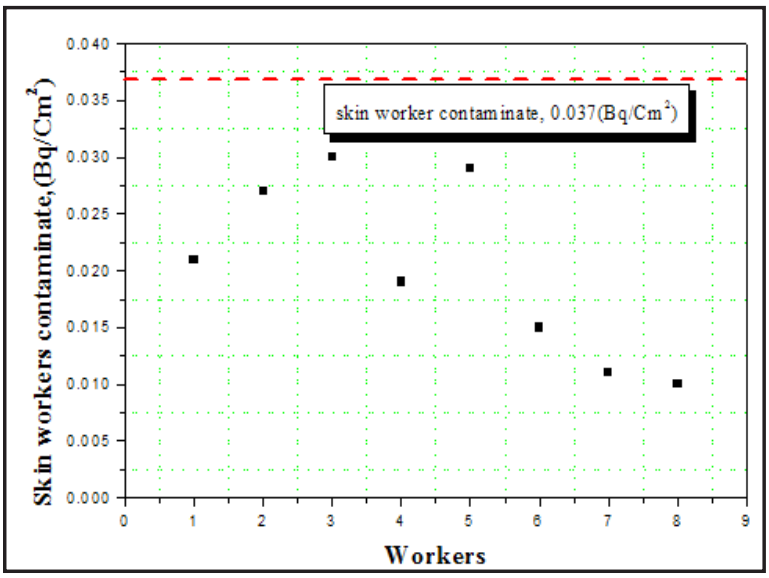

Fig. (7): skin workers contaminate.

\section{Ventilation}

Ventilation system aims to control concentration of gaseous fission product in case of fuel failure. It makes differential pressure between areas of different potential contamination. Filtration system should be provided for normal and emergency conditions. The efficiency of the ventilation system (integrity, air exchange rate, flow rates, etc.) and efficiency of filters should be routinely checked. 
From experience, it is recommended keeping free areas inside the facility positively pressurized with respect to the other areas. In the same manner, supervised and controlled areas must be are depressurized with respect to the outside with difference in the ratio according to its nature and classification to prevent the dispersion of contamination from controlled areas to supervised or from supervised to free areas. Each area may be one branch of ventilation or many branches depend on its contents.

To achieve the required values, air treatment unit equipped with suitable filters, heating/cooling coils, and a fan to drive air and distribution and recirculation ducts must be available. If the facility have similar ventilation system, it has the ability to reduce the level of contamination to values as low as possible with a view to allowing personnel access without major risks.

\section{Waste management}

The radioactive waste (RAW) is generated by the operation of the facility. RPOs must have a clear idea about the systems of (RAW) to apply the principals of the management probably. Individual and workplace monitoring are essential. The radioprotection system should perform the radiation monitoring of liquid effluent, gases, solid, areas and personnel. The facility operation aims to minimize the total amount of (RAW) produced, avoiding the unnecessary contamination of material, and ensuring adequate segregation between waste and non-disposable materials. Each (RAW) is classified and segregate at the place where it is produced, in accordance with its radioactivity and radionuclide's content. The responsibility of (RAW) must be clear, to ensure application of the local rules. To prevent the harmful, the collection, handling, treatment, conditioning, storeage, transport, and disposal of (RAW) must be performed in a manner that protects the human and the environment. Radiological hazards exist at all stages of waste handling and must be controlled. Individual monitoring includes pocket size radiation instruments for $\alpha, \beta$ and $\gamma$ radiation detection, fixed area monitoring and TLD and is the way to enhance this control.

\section{Persons who forbidden to work at supervised-and} controlled areas

Persons who are forbidden to work in supervised- and controlled areas are those workers less than 18 years old, pregnant women or mothers who are breast-feeding and personnel exceeding the maximum yearly incorporation or irradiation levels, or those having certain diseases.

\section{Personal Protective Equipment (PPE):}

(PPE) is used to protect the radiation workers from workplace hazards. Simple laboratory coats, gloves, overshoes, overheads, full protective suite with air supply, masks, aprons, arm guard, gonad protection, mammary gland protection, etc. are types of (PPE). They should be chosen in accordance with the anticipated hazards. (PPE) is used in accordance to area, the type of the task and its hazards depend on the pre-work plan. Personal monitoring equipment as external and internal dosimetry is a part of (PPE). PPE that is used in routine situations differs from those used in emergencies.

\section{CONCLUSIONS}

This paper aims to ensure that when a structuredsystem is in place is addresed radiation safety of the facility staff. Risks for categories of exposure arising from the ionizing radiation should be kept in perspective with other risks. It is important to implement an effective system of radiation protection to ensure the risks that arising from exposure to radiation remain a minor component of the spectrum of risks to which all people are exposed. Reducing these exposures is performed through the as low as reasonably achievable (ALARA) process.RPP must imply basic radiation safety that apply seriosuly. If not, severe damage to humans and the environmental probably happen. The regulatory body in Egypt (ENRRA) is responsible for the development of laws and regula- 
tions which are consistent with the laws and regulations issued by (IAEA) and (ICRP). To limit the accumulated dose over a period of time required to perform the task it is necessary to consider (TDS) depending on working conditions with pre planing. To protect the public controls at the source must be applied, using the critical groups. If the explained radiation protectionprinciples are applied by the operating authority, economic and regulatory risks will be reduce. Radiation and nuclearwaste must be also controled. Drills and exercises of the emergency plan should perform seriously. If these items are performed as explained, the applied radiation protection program is effective. Theseoutlines on protection of workersfrom ionizing radiations should be still applicable, as relevant, throughout the entire-lifetime of all facilities and activities.

\section{REFERENCES}

- Annals of the ICRP, PUBLICATION 103, the 2007 Recommendations of the International Commission on Radiological Protection, Editor: J. VALENTIN, published for the international commission on radiological protection by ELSEVIER, 2007.

- Biological Effects of Ionizing Radiation, Chapter 2, H. Domenech, Radiation Safety, DOI 10.1007/9783-319-42671-6_2, Springer International Publishing Switzerland, 2017.

- Biological Effects of Radiation, Reactor Concepts Manual, USNRC Technical Training Center, 2003.

- Essential of environmental health, second edition, chapter 8, Robert H. Friis, Jones \& Bartlett learning, 2011.

- $\quad$ Future trends in the application of isotopes and radiation, Hellmut Glubrecht, IAEA bulletin - vol.19, no.6.

- Hazrat Team, Emergency Response Manual for Class 7 Transport Emergencies, Catalogue number: INFO0764 Rev. 1, ISBN 978-1-100-11259-6, Published by the Canadian Nuclear Safety Commission (CNSC), 2008
- $\quad$ IAEA safety standards series no. GSR part 7, preparedness and response for a nuclear or radiological emergency, general safety requirement, international atomic energy agency, Vienna, 2015.

- IAEA safety standards series no. GS-R-2, preparedness and response for a nuclear or radiological emergency, safety requirement, international atomic energy agency, Vienna, 2002.

- IAEA safety standards series no. GS-R-5, predisposal management of radioactive waste, general safety requirement, international atomic energy agency, Vienna, 2009.

- IAEA safety standards series no. GS-R-4, safety assessment for facilities and activities, general safety requirement, international atomic energy agency, Vienna, 2009.

- IAEA safety standard for protecting workers and the environment, Radiation Protection and Safety of Radiation Sources: International Basic Safety Standards, General Safety Requirements Part 3, No. GSR Part3,(2008)

- Nuclear Power for Electrical Generation, Reactor Concepts Manual, USNRC Radiation Protection Series Publication, (2002)IAEA safety standard for protecting workers and the environment, Radiation Protection and Safety of Radiation Sources: International Basic Safety Standards, General Safety Requirements Part 3, No. GSR Part3.

- $\quad$ Non-Ionizing Radiations - Sources, Biological Effects, Emissionsand Exposures, Kwan-Hoong Ng, Department of Radiology, University of Malaya, Kuala Lumpur, Proceedings of the International Conference on Non-Ionizing Radiation at UNITEN(ICNIR2003), Malaysia, 2003.

- Occupational radiation protection: protecting workers against exposure to ionizing radiation, proceedings of an international conference, Vienna, Austria, IAEA, 2003.

- Recommendations for limiting exposure to ionizing radiation and National standard for limiting occupa- 
tional exposure to ionizing radiation, Radiation Protection Series Publication No. 1, NOHSC, Commonwealth of Australia, 2002.

- Sources and effects of ionizing radiation-UNSCEAR 2008, United Nations Scientific Committee on the Effects of Atomic Radiation, Volume II, Annexes C, D and E, United nations, new York, 2011.

- The benefits of nuclear energy, English edition, Bruno Comby, published by TNR Editions, 1998. 